\title{
LIFE HISTORIES OF NORTH AMERICAN GEOMETRIDAE.LLIII.
}

\author{
BY HARRISON G. DYAR, WASHINGTUN, D. C.
}

\section{Mesoleuca vasiliata Guenée.}

Egg. Elliptical, rounded, normal, the depression marked; all rounded, no flat areas; evenly reticulate with broad low lines, hexagonal, finely punctate shagreened all over. Pale waxy yellow; size $.9 \times .6 \times .5 \mathrm{~mm}$.

Stage I. Head rounded, whitish testaceous, eye black, mouth brown. Body thin and slender but not rapid in motion, becoming rigid erect when disturbed; white, the ends (joints 2-4, ro-13) yellowish tinged in certain lights from their retraction. No marks; no shields; tubercles concolorous, obscure; setae stiff, pale, rather conspicious.

Stage II. Head rounded bilobed, the apex of clypeus depressed, shining light yellow, ocelli black; width $.5 \mathrm{~mm}$. Body slender, rather elongate, normal, coarsely annulate. Setae rathercoarse, white; no shields; tubercles invisible; no marks, food green.

Stage III. Head round, bilobed, free, lobes full, shining ochraceous luteous, clypeus depressed, ocelli black; width $.8 \mathrm{~mm}$. Body moderate, green from the food, unmarked, the folded incisures whitish; tubercles a little elevated, round, shining, colorless; feet pale; no shields; setae short, pale; subventral fold prominent.

Stage $I V$. Head rounded, shining, caramel luteous, setae brown, ocelli black; width $1.1 \mathrm{~mm}$. Body cylindrical, slender, the central segments weil elongated. Translucent green, incisures narrowly folded, yellowish; tubercies small, round, white, elevated, distinct. The dorsal vessel shows darker and the tracheal line white by transparency. No marks; no shields; thoracic feet brown. About joint 9 a broad stigmatal band begins and runs to the anal feet. It is also slightly indicated on thorax. Setae moderate.

Stage $V$. Head long, bilobed, green, shagreened, the lobes full, pale greenish, the epistoma, and antennae whitish with a short white band before the eyes; width $1.7 \mathrm{~mm}$. Body moderate, elongate, cylindrical, the segments wrinkly" annulate, anal feet large, projected outwardly. (ireen, anal feet and dorsum of joint 13 shaded in vinous; tubercles elevated, rounded, white like small buttons. Very faint longitudial white washed lines; dorsal vessel dark green; setae moderately long, distinct. Later the head acquired a red flush over the lobes.

Food plant thimbleberry (Rr:bus nutkanus); the hatched larvae ate this plant and a wild larva was found on it. Larvae from Kaslo, British Columbia. 

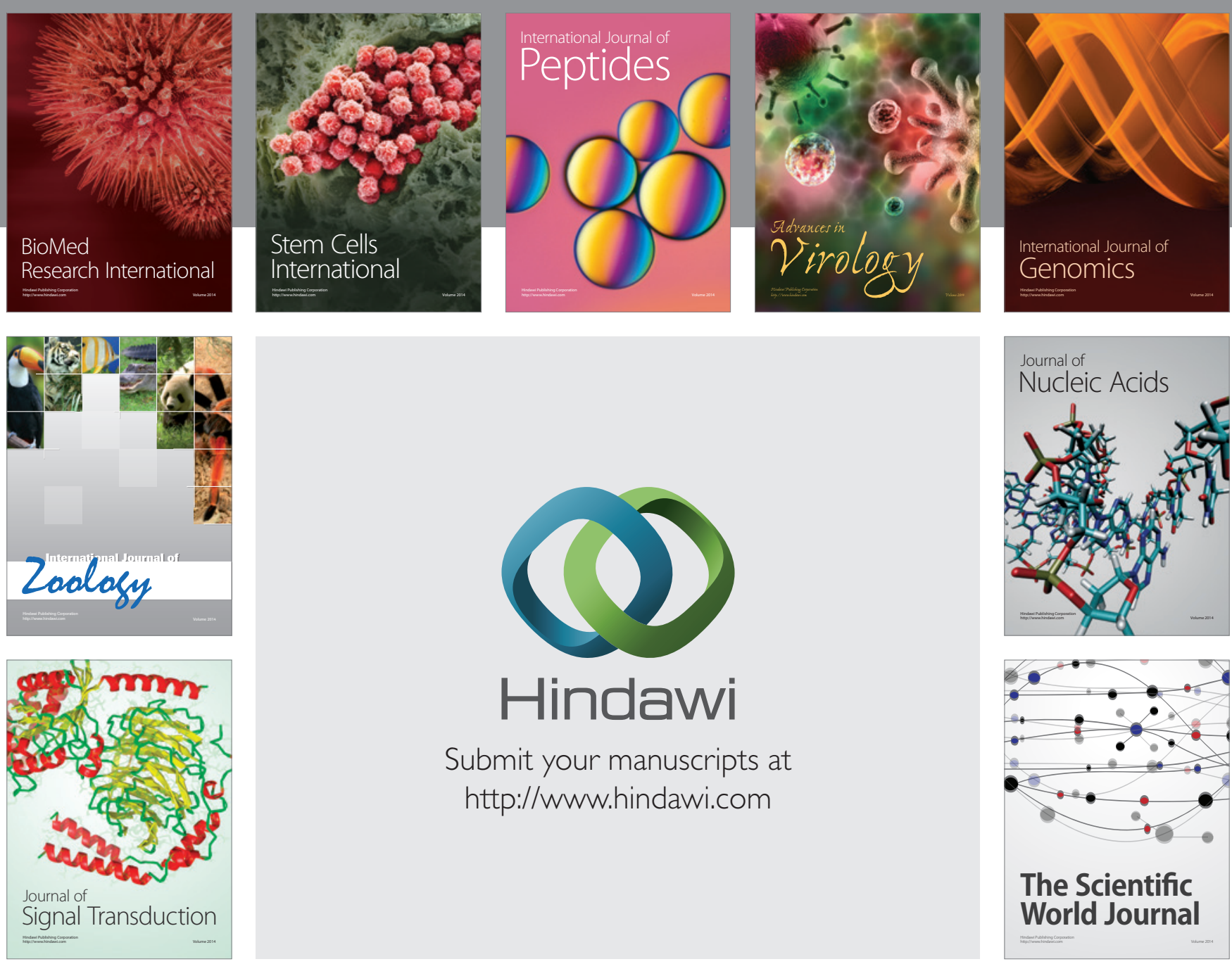

Submit your manuscripts at

http://www.hindawi.com
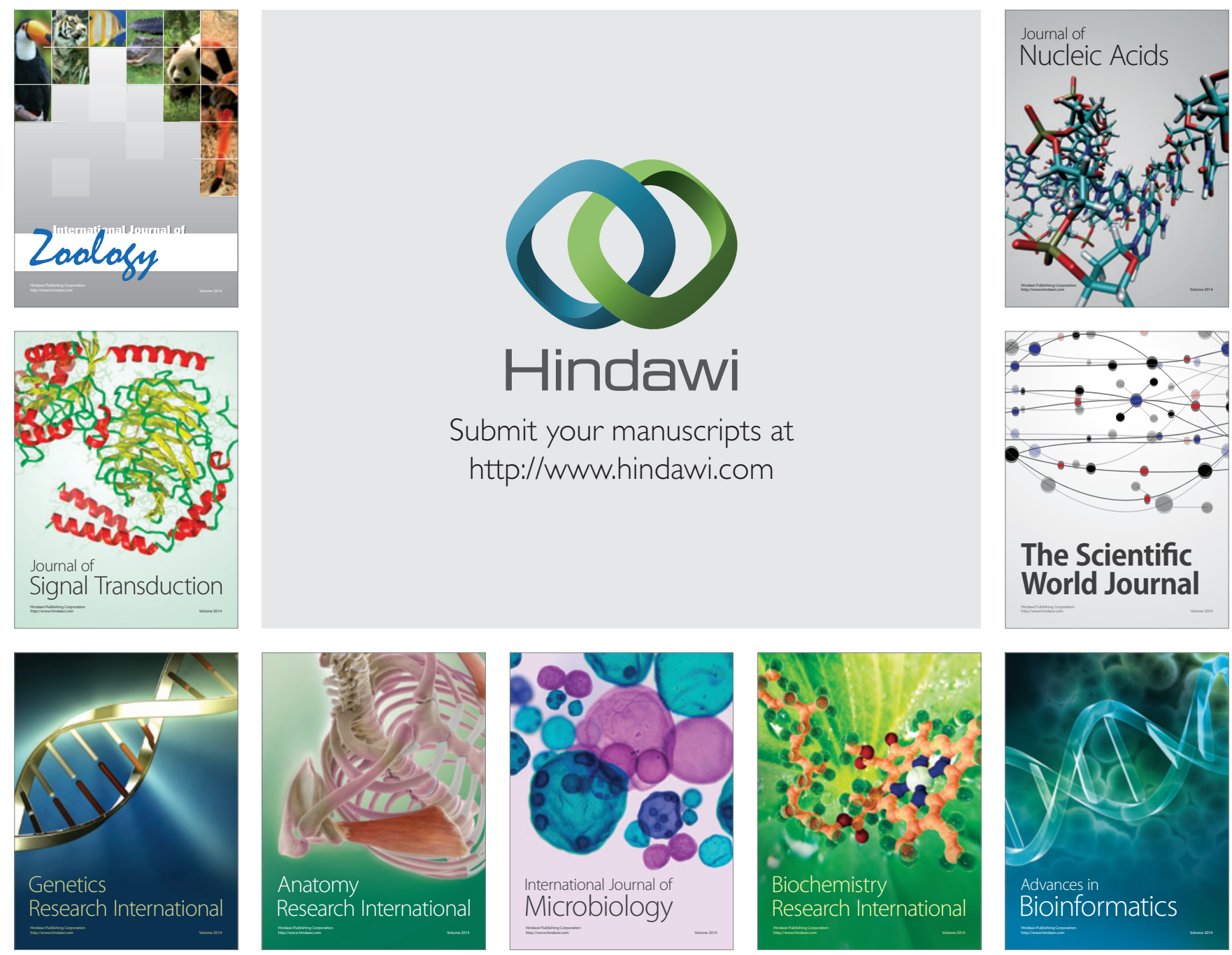

The Scientific World Journal
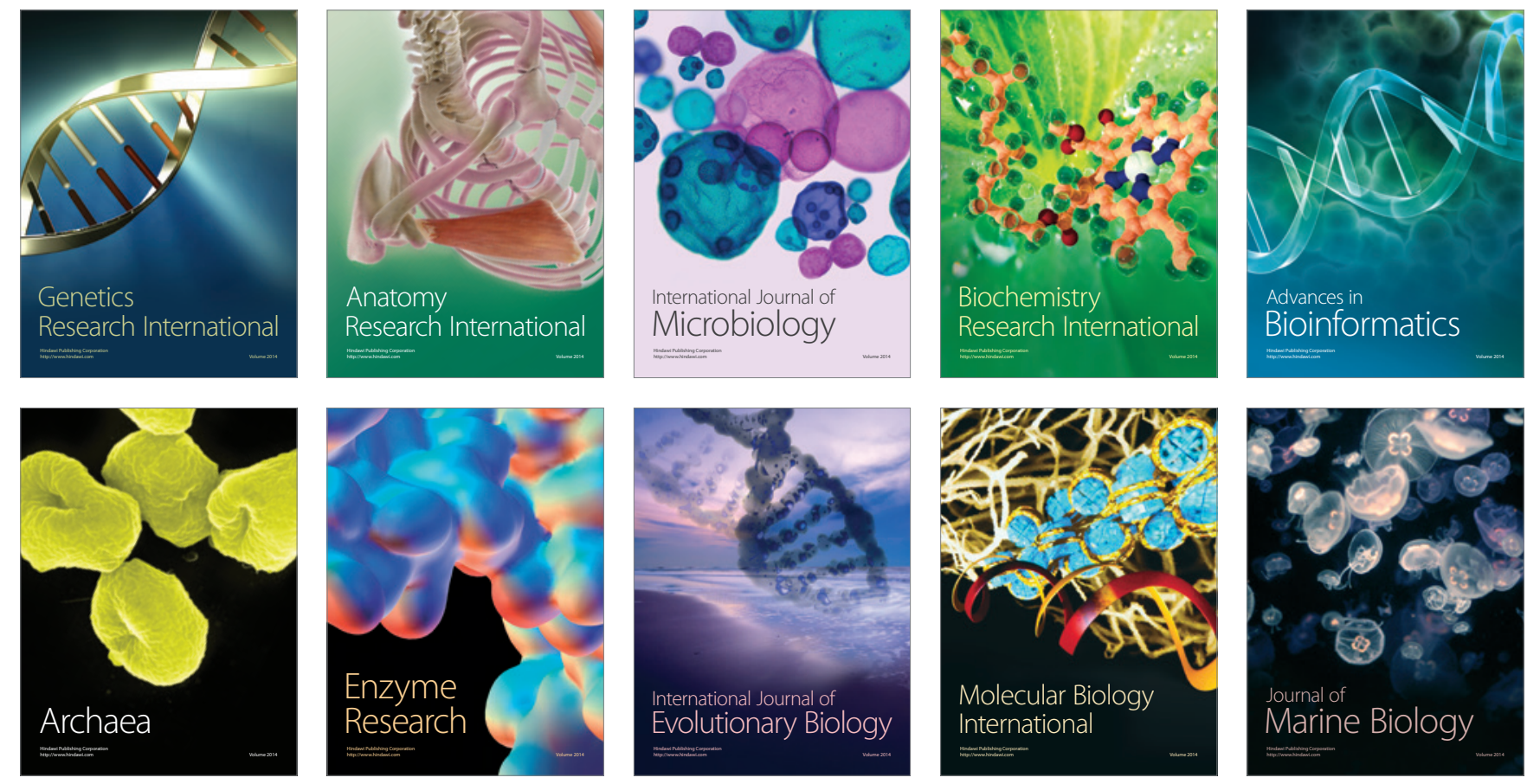